DIVISION III / WG COMMITTEE

SMALL BODIES NOMENCLATURE

LA NOMENCLATURE DES PETITS CORPS CÉLESTES

\author{
CHAIR \\ SECRETARY \\ MEMBERS
}

\author{
Jana Tichá \\ Brian G. Marsden (MPC) \\ Daniel Green (CBAT, for comet names only), \\ Rita M. Schulz (WG-PSN), \\ Michael F. A'Hearn, Julio A. Fernandez, \\ Pamela Kilmartin, Daniela Lazzaro, \\ Syuichi Nakano, Keith S. Noll, \\ Lutz D. Schmadel (editor of DMPN), \\ Viktor A. Shor, Gareth V. Williams, \\ Donald K. Yeomans, Jin Zhu
}

\title{
PROCEEDINGS OF THE BUSINESS MEETING
}

\section{Membership}

After a brief discussion it was agreed that this membership is well distributed in terms of geography, gender, and fields of planetary work.

\section{Results of previous triennium}

The Chair briefly commented on the CSBN work during the triennium. Regarding minor planets, 2511 names were approved and published in the Minor Planet Circulars. 674 comets received names, the great majority of them being SOHO comets. In accordance with its new task, the CSBN also approved the names of five satellites of minor planets. No appeals concerning CSBN decisions were reported to Division III during this triennium. The fifth edition and the Addendum 2003-2005 of the Dictionary of Minor Planet Names edited by CSBN member L. D. Schmadel have been published by Springer.

\section{Naming of "dwarf planets"}

The naming of certain special objects, notably of the "dwarf planet" 2003 UB313 and its satellite, was discussed. The process will consist of the following steps: to ask discoverer M. Brown for reasonable name proposal(s), to discuss the outcome in the CSBN and to transmit the CSBN conclusions to the WG-PSN for further consideration; the preferred name(s) will then be examined by the Division III Organizing Committee, and the choice will be passed to the IAU EC for final adoption; this whole process should be carried out as rapidly as possible because of the intense public interest, with the final name(s) approved within a month if all will go well.

\section{Satellites of minor planets}

The CSBN agreed to publish both names and citations for satellites of minor planets in the Minor Planet Circulars and the DMPN. 


\section{Limiting of names}

At the previous meeting in Sydney in 2003 the CSBN recognized the need to limit the number of namings of minor planets. It is better to concentrate on having a small number of meaningful names having broad international appeal than to name all the tens of thousands of newly numbered main-belters. During 2003-2005 individual discoverers and teams were requested to propose no more that two names each two months. The majority of them cooperated. Exceptions were allowed in a few cases, but on the whole the restriction seemed to work. At the Prague meeting the discussion on this topic continued. The most important matter seems to be to name unusual bodies of extraordinary scientific and public interest, i.e., Earth approachers, mission targets, transneptunian objects for which there have been detailed physical studies, binary or multiple systems, and so on. The CSBN members agreed to continue to examine ways of limiting the naming process by concentrating on the more significant bodies.

\section{Discussion on public access to names and citations}

This session of the Division had specially been reserved for the a discussion of the proposed definition of a planet by members of the Division.

The final matter discussed was a website containing minor planet names and citations. We are living in an "internet world" now. Members of the public ask about the meanings of specific names. There are the printed editions of the DMPN (now an official IAU reference work) as well as the batches of Minor Planet Circulars. On the other hand, one can find various websites containing citations that appear at least partly without appropriate references and acknowledgment of copyright. The CSBN members agreed to search for a satisfactory way to establish a perhaps freely available website containing names and citations, bearing in mind in particular the copyright arrangement between the IAU and Springer. 